\section{Improvement of SSCP Analysis by Use of Denaturants}

BioTechniques 27:20-24 (July 1999)

Single-strand conformation polymorphism (SSCP) analysis is a simple and quick method for mutation detection. It depends on the separation of single-stranded (ss)DNA fragments in non-denaturing polyacrylamide gels. On occasion, the ssDNA bands can be very diffuse or appear against a heavily smeared background. Here, we demonstrate that the addition of denaturants, urea or formamide, to the gels can sharpen the bands of ssDNA fragments and clear the background that might otherwise obscure bands that are diagnostic of a polymorphism.

We have recently studied seven new polymorphisms in polymerase chain reaction (PCR)-amplified fragments from the human PGMI locus (7). Two fragments, designated M3 and N1, initially gave broad or diffuse bands and heavy background smearing in the SSCP gels (Figures 1A and 2A), despite the demonstration of single intensely stained DNA bands on electrophoresis in agarose gel (data not shown), and native and denaturing polyacrylamide gels (Figure 3). We hypothesized that the smearing was due to the occurrence of multiple conformations of ssDNA with similar, but not identical, electrophoretic mobilities. We theorized that a mildly denaturing environment in the gel would make the multiple conformations move with a more uniform mobility by reducing their number, and this could clear the background smearing and improve the resolution.

With the M3 fragment (54\% GC content), a pronounced improvement in the resolution of the ssDNA bands was obtained with $10 \%$ (wt/vol) urea or $10 \%$ ( $\mathrm{vol} / \mathrm{vol})$ formamide in the gel though the relative mobilities of the variant bands were reversed (Figure 1B). Slight improvement in resolution was also obtained with $10 \%$ (vol/vol) dimethyl sulfoxide (DMSO), but here the bands retained their original relative mobilities and were still somewhat blurred.

With the N1 fragment (77\% GC con- tent), considerable improvement in the resolution of the bands was obtained with urea or formamide, but not DMSO. The gel concentration of formamide was titrated in $5 \%$ incremental steps from $10 \%-30 \%$ to find the optimum conditions (Figure 2). In the absence of formamide, the bands of both the $\mathrm{C}$ and $\mathrm{D}$ alleles were very diffuse, and the $\mathrm{C}$ band was in the center of the smeared regions associated with the $\mathrm{A}$ and $\mathrm{B}$ bands. Therefore, it was not possible to type the $\mathrm{C}$ and $\mathrm{D}$ alleles. As the formamide concentration was increased, three effects were evident: ( $i$ ) the sharpening of the $\mathrm{C}$ and $\mathrm{D}$ bands, (ii) the clearing of the background smearing and (iii) the appearance of some additional bands. At a formamide concentration above $20 \%$, the relative mobilities of the A and B bands were reversed.
The use of denaturants in SSCP gels was first reported by Glavac and Dean (2) when they were exploring optimization strategies in SSCP analysis. Three other groups also reported the use of formamide (but not urea) in SSCP analysis $(3,5,6)$, and one of these claimed that genotyping was easier in the presence of formamide (3). Recently, addition of sodium dodecyl sulfate (SDS) (1) or polyethylene glycol (PEG) (4) in the gel has also been found to enhance the technique. The use of strong denaturants in the gels seems to contradict the basic working principles of the SSCP technique. However, we have shown that the incorporation of denaturants in SSCP gels can lead to significant enhancement of resolution, clearance of background smearing and changes in rela-

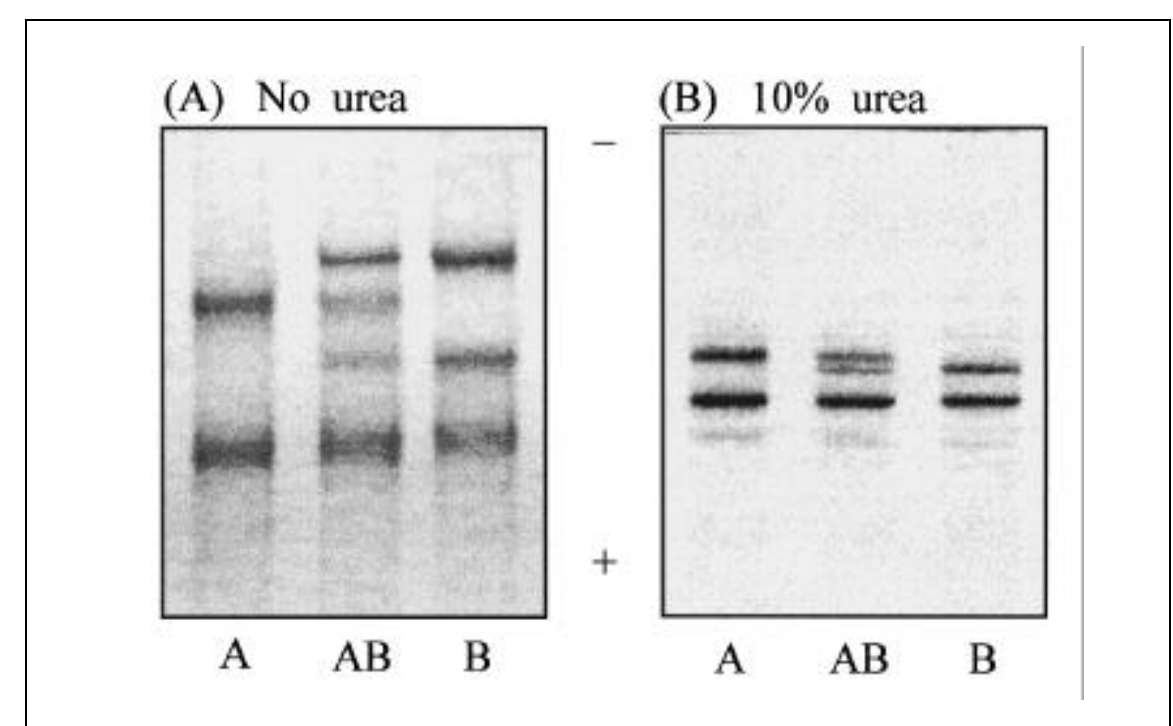

Figure 1. SSCP analysis of the M3 fragment in the absence (A) and the presence (B) of $10 \%$ urea. The phenotypes of the polymorphism are shown below each gel. The fragment ( $232 \mathrm{bp}$ ) was amplified in a reaction vol of $25 \mu \mathrm{L}$ containing $1 \times$ reaction buffer $\left(50 \mathrm{mM} \mathrm{KCl}, 10 \mathrm{mM}\right.$ Tris- $\mathrm{HCl}, \mathrm{pH} 9.0$ at $25^{\circ} \mathrm{C}$ and $0.1 \%$ Triton $\left.{ }^{\circledR} \mathrm{X}-100\right), 1.5 \mathrm{mM} \mathrm{MgCl}_{2}, 0.2 \mathrm{mM}$ for each dNTP, $0.3 \mu \mathrm{M}$ for each primer, $50-100 \mathrm{ng}$ of genomic DNA and 0.5 U of Taq DNA Polymerase (Promega, Southampton, England, UK). The enzyme was added during the initial denaturation phase of $95^{\circ} \mathrm{C}$ for $5 \mathrm{~min}$, and amplification was carried out for $35 \mathrm{cy}-$ cles of $95^{\circ} \mathrm{C}$ for $20 \mathrm{~s}, 60^{\circ} \mathrm{C}$ for $20 \mathrm{~s}$ and $72^{\circ} \mathrm{C}$ for $25 \mathrm{~s}$. The primers were Y6iF2 $\left(5^{\prime}\right.$-TGT CTT AGG TCG TCC CAG TCT TCA C-3') and Y6iR2 (5'-GCA GCC CAT CAA GAA AAC AGC TAC T-3'). For SSCP, $2 \mu \mathrm{L}$ of PCR product were mixed with $2 \mu \mathrm{L}$ distilled water and $4 \mu \mathrm{L}$ of loading solution (95\% formamide, $20 \mathrm{mM}$ EDTA and $0.05 \%$ each of bromophenol blue and xylene cyanol FF). The mixtures were heated at $95^{\circ} \mathrm{C}$ for $7 \mathrm{~min}$ and immediately cooled in ice water before loading. Electrophoresis was carried out in a Hoefer ${ }^{\mathrm{TM}}$ SE 600 Series tank (Amersham Pharmacia Biotech, Little Chalfont, Bucks, England, UK), at $400 \mathrm{~V}$ for $3.5 \mathrm{~h}$ at $25^{\circ} \mathrm{C}$ in polyacrylamide gels (dimensions $160 \times 140 \times 0.75$-mm cast between $3.0-\mathrm{mm}$ thick glass plates) of $10 \% \mathrm{~T}, 2.6 \% \mathrm{C}$ with $5 \%$ (vol/vol) glycerol and with or without $10 \%$ (wt/vol) urea. The gel was prepared using separate $40 \%(\mathrm{wt} / \mathrm{vol})$ acrylamide and $2 \%(\mathrm{wt} / \mathrm{vol})$ bis solutions (both from BDH Chemicals, Poole, Dorset, England, UK). Buffer in the gel and the tank was $1 \times$ TBE buffer $(89 \mathrm{mM}$ Tris, $89 \mathrm{mM}$ boric acid, $2.5 \mathrm{mM} \mathrm{Na}_{2}$ EDTA, $\mathrm{pH}$ 8.3). The required buffer temperature was maintained by connecting the heat exchanger of the Hoefer tank to an external thermostatically controlled circulator. The bands were visualized by silver staining. Though not shown here, it is interesting to note that the bands were much more diffuse at low than at high temperature, and that this polymorphism was not revealed at all when the fragment was analyzed in the presence of $10 \%$ urea alone (i.e., without glycerol). 


\section{Benchmarks}

(A) No formamide

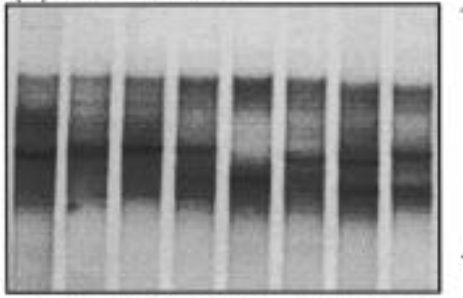

A $\quad A B \quad B \quad B C \quad C \quad A C A D \quad B D$

(C) $20 \%$ formamide

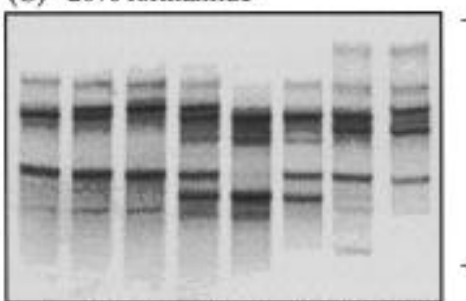

A $A B \quad B \quad B C \quad C \quad A C A D B D$
(B) $10 \%$ formamide

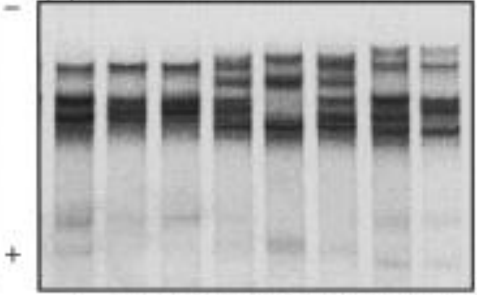

A $\quad A B \quad B \quad B C \quad C \quad A C A D B D$

(D) $30 \%$ formamide

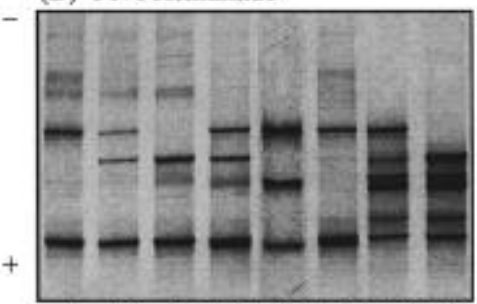

A $A B \quad B \quad B C \quad C \quad A C A D \quad B D$

Figure 2. Optimization of SSCP condition by titrating the concentration of formamide in the gel for the $\mathbf{N} 1$ fragment. The phenotypes of the polymorphism are indicated below each gel. The PCR mixture was the same as for Figure 1, except that $\mathrm{MgCl}_{2}$ was at $2.5 \mathrm{mM}$, and $5 \%$ (vol/vol) formamide and 5\% ( $\mathrm{vol} / \mathrm{vol}$ ) glycerol were incorporated in the reaction mixture to facilitate the amplification of this GC-rich fragment ( $293 \mathrm{bp}$ ). The initial denaturation phase consisted of $95^{\circ} \mathrm{C}$ for $5 \mathrm{~min}, 80^{\circ} \mathrm{C}$ for $2.5 \mathrm{~min}$ and $95^{\circ} \mathrm{C}$ for $1.5 \mathrm{~min}$, and Taq DNA polymerase was added only when the temperature dropped to $80^{\circ} \mathrm{C}$. Amplification was carried out for 35 cycles of $95^{\circ} \mathrm{C}$ for $30 \mathrm{~s}, 63^{\circ} \mathrm{C}$ for $1 \mathrm{~min}$ and $72^{\circ} \mathrm{C}$ for $1 \mathrm{~min}$. The primers were Y1iF1 (5'-GCC AAC GGG GTA AGG GAT GC- $\left.3^{\prime}\right)$ and Y1iR1 (5'-GGA GAG TCG GGC GTG ACC TT-3'). The SSCP analysis was performed as indicated in Figure 1, except that electrophoresis was carried out for $13 \mathrm{~h}$ at $4{ }^{\circ} \mathrm{C}$ in a cold room in gels of $12 \% \mathrm{~T}, 2.6 \% \mathrm{C}$ containing various concentrations of formamide: (A) $0 \%$, (B) $10 \%$, (C) $20 \%$ and (D) $30 \%$

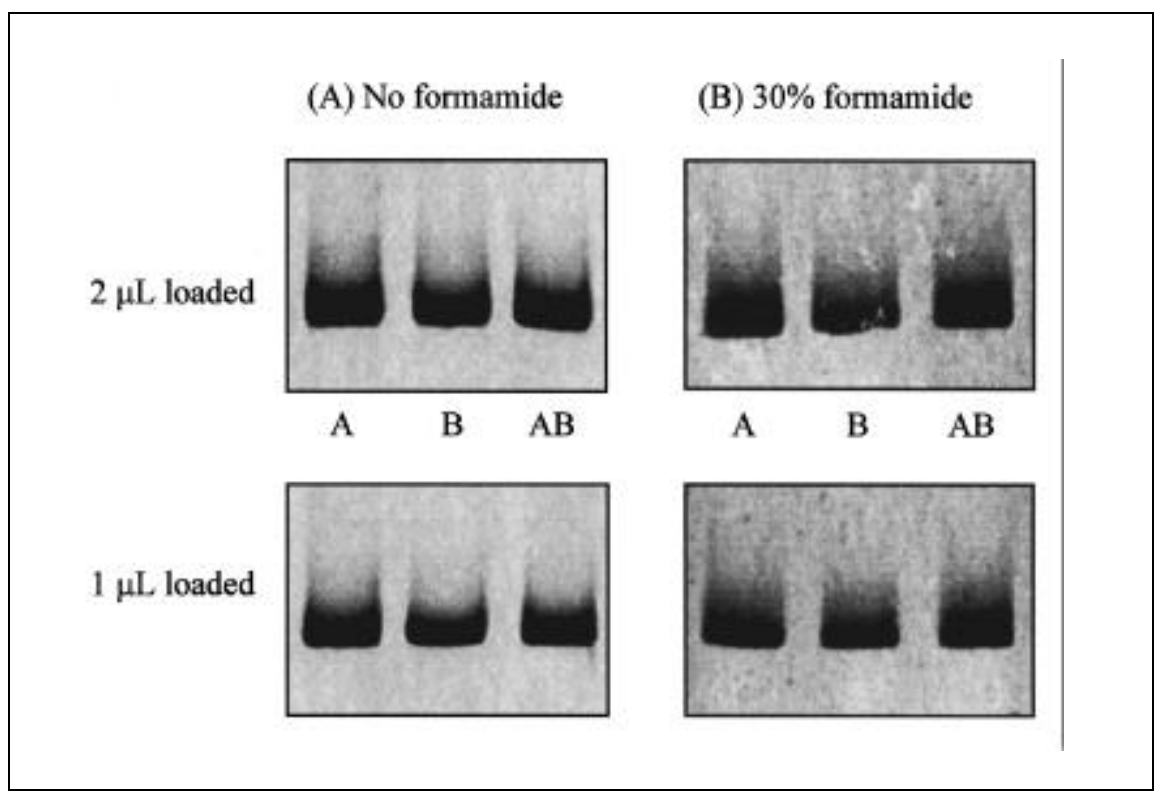

Figure 3. Demonstration of the purity of the N1 PCR products using native and denaturing polyacrylamide gels. The phenotypes of the samples are indicated below each gel. Undenatured PCR products were electrophoresed for $2.5 \mathrm{~h}$ at $400 \mathrm{~V}$ at room temperature in (A) native and (B) denaturing (with $30 \%$ formamide) polyacrylamide gels of $12 \% \mathrm{~T}, 2.6 \% \mathrm{C}$ using the Hoefer SE 600 tank. The $1 \times \mathrm{TBE}$ buffer was used in both the gel and the tank. The bands were visualized by silver staining. Note the presence of a slower moving heteroduplex band in the heterozygous sample in the denaturing gel.

tive electrophoretic mobilities. These effects are to some extent dependent on the gel temperature. The N1 polymorphism illustrated here was hardly recognized at $20^{\circ} \mathrm{C}$ (data not shown), but it was very clear at $4^{\circ} \mathrm{C}$ in the presence of $30 \%$ formamide (Figure 2D). DMSO failed to produce the same effects as formamide and urea, probably because of its milder denaturing properties.

There are several general ways to tackle the problems of diffuse bands and background smearing in SSCP analysis. Gels with higher concentrations of acrylamide and crosslinker usually sharpen the bands slightly. Alterations in gel temperature can also sharpen the bands, but can sometimes reduce the separation between them and render the polymorphism undetectable. Another strategy is to design new primers to amplify a different but overlapping fragment, however this requires the knowledge of the polymorphic mutation site(s). Furthermore, there is no guarantee that a new fragment will give sharper bands. The addition of formamide or urea to an SSCP gel is thus a simple, quick and inexpensive option when attempting to sharpen bands and reduce smearing. We have found that this is a particularly useful modification of the SSCP technique when a large number of samples need to be screened. Optimization can be increased if one uses a continuous transverse gradient of the denaturant in the gel (5) instead of stepwise increments.

\section{REFERENCES}

1.Blancé, H., C. Valette and C. BellannéChantelot. 1997. Optimization of nonisotopic PCR-single-strand conformation polymorphism analysis. Clin. Chem. 43:2190-2192.

2.Glavac, D. and M. Dean. 1993. Optimization of the single-strand conformation polymorphism (SSCP) technique for detection of point mutations. Hum. Mutat. 2:404-414.

3.Kumeda, Y. and T. Asao. 1996. Single-strand conformation polymorphism analysis of PCRamplified ribosomal DNA internal transcribed spacers to differentiate species of Aspergillus Section Flavi. Appl. Environ. Microbiol. 62:2947-2952.

4.Markoff, A., A. Savov, V. Vladimirov, N. Bogdanova, I. Kremensky and V. Ganev. 1997. Optimization of single-strand conformation polymorphism analysis in the presence of polyethylene glycol. Clin. Chem. 43:30-33.

5.Paccoud, B., J. Bourguignon, M. DiarraMehrpour, J.-P. Martin and R. Sesboüé. 
1998. Transverse formamide gradients as a simple and easy way to optimize DNA singlestrand conformation polymorphism analysis. Nucleic Acids Res. 26:2245-2246.

6.Yamashita, K., T. Tatebayashi, H. Shinoda and I. Okayasu. 1996. Simplified rapid nonradioactive PCR-SSCP method applied to Kras mutation analysis. Pathol. Int. 46:801-804.

7.Yip, S.P., W. Putt, D.A. Hopkinson and D.B. Whitehouse. 1999. Identification and characterization of polymorphisms in human phosphoglucomutase (PGM1). Ann. Hum. Genet. 63:129-140.

S.P. Yip was a recipient of the Commonwealth Academic Staff Scholarship and was on leave from his home university, the Hong Kong Polytechnic University, during the study. Address correspondence to Dr. David B. Whitehouse, MRC Human Biochemical Genetics Unit, the Galton Laboratory, University College London, Wolfson House, 4 Stephenson Way, London NW1 2HE, England, UK. Internet: d.whitehouse@galton. ucl.ac.uk

Received 16 October 1998; accepted 6 April 1999.

\author{
Shea Ping Yip, 1,2 David A. \\ Hopkinson $^{1}$ and David B. \\ Whitehouse $^{1}$ \\ ${ }^{1}$ University College \\ London, England, UK \\ ${ }^{2}$ Hong Kong Polytechnic \\ University \\ Hong Kong, PR China
}

\section{Subcellular Fractionation of Group B Streptococcus}

BioTechniques 27:24-28 (July 1999)

Streptococcus agalactiae or group B Streptococcus (GBS) is a gram-positive bacterium that causes significant infant morbidity and mortality (1). Vaccine conjugates comprising capsular polysaccharides and protein antigens are currently under development (4). Analysis and characterization of streptococcal antigens for vaccine development have suffered from a lack of standardized techniques to determine subcellular lo- calization. We describe a method to fractionate GBS into its subcellular components to determine the localization of protein and polysaccharide antigens. This information can be used to study mechanisms of protein and polysaccharide expression in these organisms and ultimately to help identify useful targets for vaccine development.

The subcellular fractionation of GBS used methods originally developed for the gram-positive coccus Staphylococcus aureus (13). However, because of apparent differences between the peptidoglycans of GBS and $S$. aureus, the muralytic enzyme mutanolysin was used to solubilize the cell wall $(2,3,8)$. GBS was grown overnight on trypticase soy agar plates with $5 \%$ sheep's blood. Colonies were removed from the plate with a sterile cotton swab, inoculated into Todd-Hewitt broth (Becton Dickinson Microbiology Systems, Sparks, MD, USA) and grown to an optical density $(O D)_{600} \cong$ 0.5 at $37^{\circ} \mathrm{C}$. Cells were placed on ice, and $1-\mathrm{mL}$ aliquots were transferred to pre-chilled microcentrifuge tubes and centrifuged at $14000 \times g$ for $3 \mathrm{~min}$ at $4{ }^{\circ} \mathrm{C}$. The supernatant was removed, transferred to a fresh tube and frozen at $-80^{\circ} \mathrm{C}$ (spent-medium cell fraction). The cell pellet was resuspended in 0.5 $\mathrm{mL}$ of ice-cold protoplasting buffer: $40 \%$ sucrose in $0.1 \mathrm{M} \mathrm{KPO}_{4}(\mathrm{pH} 6.2)$ containing the protease inhibitors 0.029 $\mathrm{mM}$ pepstatin $\mathrm{A}, 0.05 \mathrm{mM}$ phenylmethylsulfonyl fluoride (PMSF), 1.25 $\mathrm{mM}$ iodoacetic acid and $1.25 \mathrm{mM}$ ben-

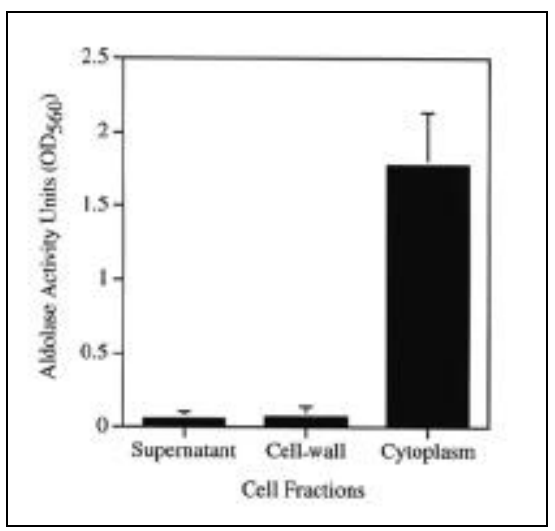

Figure 1. Aldolase levels in GBS subcellular fractions. Mean levels of the total aldolase activity in each cell fraction of GBS. Y-axis indicates total absorbance units at $560 \mathrm{~nm}$ (see text). Error bars represent standard deviations of duplicate samples from two independent experiments. zamidine. GBS cell walls were solubilized by the addition of $170 \mathrm{U}$ of mutanolysin (M990; Sigma, St. Louis, MO, USA) from a stock solution of $3400 \mathrm{U} / \mathrm{mL}(50 \mu \mathrm{L}$ of $1 \mathrm{mg} / \mathrm{mL}$ stock) and digestion for $10 \mathrm{~min}$ at $37^{\circ} \mathrm{C}$. The length of time needed to form protoplasts was determined empirically by digestion of GBS for 2-30 min and observation of protoplast formation by dark-field microscopy. The protoplasts were centrifuged at $14000 \times g$ for $3 \mathrm{~min}$ at $4^{\circ} \mathrm{C}$, and the supernatant was transferred to a fresh tube and frozen (cellwall fraction). The cell pellets (protoplasts) were lysed by resuspension in $250 \mu \mathrm{L}$ of membrane buffer $(100 \mathrm{mM}$ $\mathrm{NaCl}, 100 \mathrm{mM}$ Trizma, pH 7.5, 10 mM $\mathrm{MgCl}_{2}$ ), quick-frozen in a dry iceEtOH bath for approximately 2-3 min followed by thawing for 2-3 $\mathrm{min}$ at $37^{\circ} \mathrm{C}$. This freeze-thaw cycle was repeated $3 \times$ to thoroughly lyse the protoplasts. The cell membranes were separated from the cytoplasmic fraction by ultracentrifugation at $436000 \times g$ at $4^{\circ} \mathrm{C}$ for $30 \mathrm{~min}$. The supernatant (cytoplasmic fraction) was transferred to a fresh tube and frozen, and the pellet (membrane fraction) was discarded.

To determine the purity of the subcellular fractions, activity levels of the intracellular enzyme aldolase and lev-

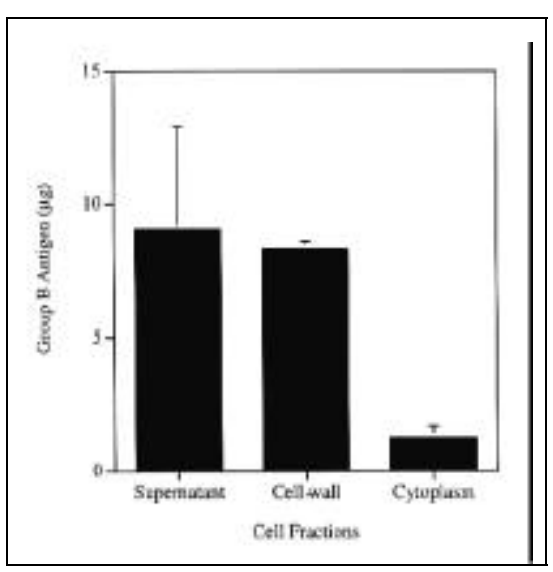

Figure 2. Group B polysaccharide levels in GBS subcellular fractions. Levels of total group $B$ antigen as determined by ELISA inhibition for the different cell fractions of GBS. ELISA plates were coated with group $B$ polysaccharide conjugated to human serum albumin (B-HSA) (9). Antibodies specific for the group B polysaccharide were used to bind the immobilized B-HSA. The amount of inhibition was proportional to the concentration of group B antigen in each cell fraction. Error bars represent standard deviation of duplicate samples from two independent experiments. 